\title{
Assessment of maternal deaths using three delay model at a tertiary care centre in rural Maharashtra, India: retrospective six years study
}

\author{
Jitendra P. Ghumare ${ }^{1,2 *}$, Namrata Vasant Padvi
}

\begin{abstract}
${ }^{1}$ Associate Professor and Nodal Officer, Maternal Mortality Committee, ${ }^{2}$ Department of Obstetrics and Gynecology,
\end{abstract} Shri Bhausaheb Hire Government Medical College, Dhule, Maharashtra, India

Received: 20 June 2018

Accepted: 30 June 2018

\section{*Correspondence:}

Dr. Jitendra P. Ghumare,

E-mail: drjitendraghumare2011@gmail.com

Copyright: ( $\odot$ the author(s), publisher and licensee Medip Academy. This is an open-access article distributed under the terms of the Creative Commons Attribution Non-Commercial License, which permits unrestricted non-commercial use, distribution, and reproduction in any medium, provided the original work is properly cited.

\begin{abstract}
Background: Maternal deaths are the social indicators of the human development and hence their place in MDGs and now in SDGs. Even though India has made a great stride in reducing maternal deaths, the differentials in the states are huge ranging from 46 to 237 maternal deaths per 100000 live births. The three delay model assesses the issues in the emergency obstetric care and upon which the interventions can be based to improve maternal health indicators.

Methods: Retrospective record based observational study was carried out at an obstetrics and gynecology department of a tertiary care hospital located at Northern Maharashtra region. The records of deliveries, maternal deaths, age of the mothers, their time of presentation with obstetric complication, level of delay and the reason for delay were extracted for the period of 2011 to 2016. Three delays being, level I - delay in decision to seek care, level II - delay in identifying and reaching medical facility, level III - delay in receipt of adequate and appropriate treatment at facility.

Results: Out of 54335 deliveries, there were 128 maternal deaths. $80 \%$ women died due to complication in their ANC, 55\% being in the third trimester of ANC. Major causes of death were preventable, including Eclampsia (21\%), Anaemia (17\%), PIH (15\%), Sepsis, Other infections and haemorrhage. 27\% women had delay of level I, 21\% had level III and $15 \%$ had a mix of two or three level of delays. The reasons for level I delay being Lack of ANC visits, no ANC registration, level II delay being lack of timely transport facility, level III delay being lack of adequate manpower, training, and lack of efficient intensive care facilities.

Conclusions: A good quality emergency obstetric care equals good maternal health. It can be achieved by strengthening the health infrastructure, tackling manpower shortages, having better referral linkages.
\end{abstract}

Keywords: EmOC, Maternal death, Maternal mortality rate, Three delays

\section{INTRODUCTION}

Maternal Mortality Rates (MMR) through the regions, countries and the communities can be a measure for the inequities in the health care access. ${ }^{1}$ MMR as monitored by the MDGs has declined worldwide from 385 in 1990 to 216 deaths per 100000 live births in 2015 , median rate of decline being $2.9 \%$ from 2000 to $2010 .^{2}$

India's latest figures indicate a further decline from the earlier numbers, the MMR reduced to 130, although the differences in various Indian states being huge, Kerala having MMR of 46 to Assam being at 237. ${ }^{3}$ Many interventions have been initiated and strengthened to prevent maternal deaths in India directly and indirectly. ${ }^{4}$

The three delay model can be applied to understand the causes of delays in emergency obstetric care which may lead to maternal deaths, eventually calling for interventions to avoid those delays. ${ }^{5}$ This study has been conducted in a tertiary care hospital in the rural area of Northern Maharashtra, to analyse the pattern of the 
delays in the current scenario where maternal death is one of the top priorities of development for the country and the world.

\section{METHODS}

The present retrospective record based observational study was carried out at an obstetrics and gynecology department of a tertiary care hospital attached to government medical college, located in Northern Maharashtra region which is a rural area.

Maternal death is defined as "as death of a woman while pregnant or within 42 days of termination of pregnancy, irrespective of the duration and site of pregnancy, from any cause related to or aggravated by pregnancy or its management but not from accidental or incidental causes" (ICD-10).

Authors used the three-delay model in which maternal death were classified into three delays, delay pertaining to the emergency obstetric care. Delay of Level 1 is decision to seek care, level 2 is identifying and reaching medical facility and level 3 is receipt of adequate and appropriate treatment at facility. ${ }^{5}$

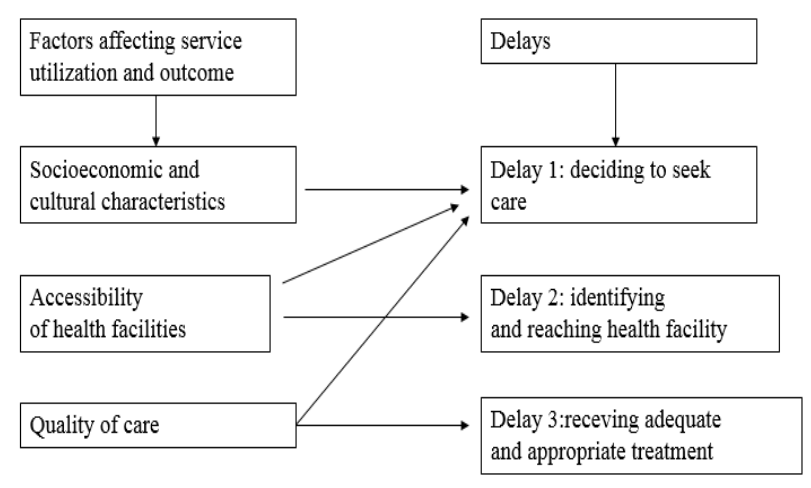

Figure 1: The three delay model.

\section{Inclusion criteria}

- All the deaths pertaining to maternal death were included for study purpose.

\section{Exclusion criteria}

- The cases referred from our hospital to next higher centre or against medical advice were excluded.

The study extracted the information from the records during the period from 2011 to 2016. Information included year wise number of deliveries conducted in the hospital, year wise number of maternal deaths, time of presentation of the women for obstetric care to the tertiary care facility, cause of death, level of delay with the reason/s for delay.

\section{Statistical analysis}

All the collected data entered, cleaned and analyzed using Microsoft $^{\mathrm{TM}}$ Excel 2010. Descriptive analysis which includes frequency distribution showing number and percent- ages were generated for each identified variable.

\section{RESULTS}

A total of 54335 deliveries were conducted through the period, 2011 to 2016 at the tertiary care hospital. 128 Maternal deaths were reported out of these deliveries. (Table 1).

Table 1: Year wise deliveries and maternal deaths reported at the institute.

\begin{tabular}{|c|c|c|}
\hline Year & Total no. of deliverie & Maternal death \\
\hline 2011 & 8116 & 23 \\
\hline 2012 & 9072 & 20 \\
\hline 2013 & 8918 & 15 \\
\hline 2014 & 9190 & 21 \\
\hline 2015 & 9892 & 24 \\
\hline 2016 & 9147 & 25 \\
\hline Total & 54335 & 128 \\
\hline
\end{tabular}

Table 2: Demographic and obstetric profile of maternal deaths.

\begin{tabular}{|c|c|c|c|}
\hline $\begin{array}{l}\text { Maternal } \\
\text { details }\end{array}$ & & Numbers & Percent \\
\hline \multirow{5}{*}{$\begin{array}{l}\text { Age group } \\
\text { (Yrs) }\end{array}$} & $\leq 20$ & 36 & 28 \\
\hline & $21-25$ & 58 & 45 \\
\hline & $26-30$ & 25 & 20 \\
\hline & $31-35$ & 7 & 6 \\
\hline & $>35$ & 2 & 2 \\
\hline \multirow{3}{*}{$\begin{array}{l}\text { Time of } \\
\text { presentation }\end{array}$} & ANC & 98 & 80 \\
\hline & Intra-Partum & 16 & 13 \\
\hline & PNC & 8 & 7 \\
\hline \multirow{4}{*}{$\begin{array}{l}\text { Time of } \\
\text { presentation } \\
\text { for ANC in } \\
\text { trimester }\end{array}$} & I trimester & 1 & 1 \\
\hline & II trimester & 20 & 20 \\
\hline & III trimester & 54 & 55 \\
\hline & $\begin{array}{l}\text { Week not } \\
\text { mentioned }\end{array}$ & 23 & 23 \\
\hline
\end{tabular}

Table 2 shows the details of the mother in terms of age, time of presentation and the trimester in case of ANCs. $45 \%$ of the deaths belonged to the $21-25$ age group of women, followed by those less than 21 years $(28 \%)$. Of the 128 maternal deaths, time of presentation was available in the records in 122 cases. Most of the 122 cases presented in their ANC period (80\%), of which $55 \%$ came in the third trimester. In 23 cases, the week was not mentioned, and only 1 woman presented in I trimester.

Cause of death was mentioned in 118 cases of maternal deaths, table 3 gives the details of the same. Eclampsia $(21 \%)$ was the major cause of death, followed by severe 
anaemia (17\%) and pregnancy induced hypertension $(15 \%)$. Other important causes of death were intrauterine fetal death leading to sepsis, post-partum haemorrhage (PPH), infectious diseases, respiratory distress, septicaemia and uterine rupture (Table 3 ).

Table 3: Distribution of maternal deaths by cause $(n=118)$.

\begin{tabular}{|lll|}
\hline Cause of death & Numbers & Percentage \\
\hline Eclampsia & 27 & 18 \\
\hline Severe anemia & 21 & 14 \\
\hline PIH & 19 & 12 \\
\hline $\begin{array}{l}\text { Intrauterine fetal death } \\
\text { and sepsis }\end{array}$ & 13 & 8 \\
\hline $\begin{array}{l}\text { Post-Partum } \\
\text { haemorrhage }\end{array}$ & 11 & 7 \\
\hline Infectious disease & 11 & 7 \\
\hline Respiratory distress & 10 & 6 \\
\hline Sepsis & 9 & 6 \\
\hline Uterine rupture & 4 & 3 \\
\hline Other & 18 & 12 \\
\hline Cause not mentioned & 10 & 6 \\
\hline
\end{tabular}

Table 4 shows the level of delays reported in the maternal deaths. $27 \%$ delays are in the level 1 where the decision to seek care by the patient has been a delay, whereas $21 \%$ of the delays are in the level 3 where the woman did not get emergency care at tertiary centre.

About $19 \%$ of the delays were a mix of the three types of delays, either any two or all three. For $15 \%$ of the women, there was no delay and for another $15 \%$, the level of delay was not documented. The level 1 delay was mostly seen with respect to No ANC registration, lack of ANC visits. Level 3 delays were majorly seen with inadequate facilities with respect to dedicated Obstetric ICU, lack of sufficient beds at the main ICU, inadequate specialist services, inadequate blood component/ transfusion facility, inadequate staff at the tertiary care hospital.

\section{DISCUSSION}

Most maternal deaths occur due to the preventable causes. ${ }^{6}$ Of the various factors affecting maternal death, those which have an impact on the time period between onset of obstetric complications and its outcome are the most important. The three delays try to focus on these factors, and which furthermore give us the more insight on the specific levels of interventions. ${ }^{5}$ To understand the causes of such as Hemorrhage, Eclampsia, Anaemia, and Sepsis are what underline this study, being conducted in a tertiary care hospital attached to a government medical college in the North of Maharashtra in a rural area. The study period was 2011 to 2016 .

Maternal mortality Ratio for the study of average 235 per 100000 deliveries is much higher than the average of state of Maharashtra of 61 per 100000 live births as documented in SRS. ${ }^{3}$ Although, it is a tertiary care hospital where many cases reach after a referral, the maternal mortality is very high. This type of variation in the state is what is needed to be focused upon, to lower the averages further and to achieve the SDGs and better maternal health.

The maximum deaths are occurring in the 21 to 25 years of age group, wherein also most pregnancies occur. This finding is similar to the country figures, as well as similar proportion was seen in a western Maharashtra semi-urban area tertiary care hospital. ${ }^{7}$ Rest of the age groups also show similar trends as are seen in the country level as reported by SRS.

Causes of death as seen in the study are mostly preventable, viz., Eclampsia, PIH, Haemorrhage, Infections, Anaemia. ${ }^{6}$

Haemorrhage, infections can be prevented and treated if the woman reaches the health care facility in time and gets appropriate and quality care. Pregnancy related hypertension, Pre-Eclmapsia can be diagnosed early and if treated well, Eclampsia can be prevented. Anaemia in pregnancy can be prevented with regular ANC visits and severe forms treated adequately with adequate transfusion facilities. ${ }^{6}$ Also, in above causes, the role of a wellequipped health facility with a good referral network plays an important role in preventing the maternal deaths. Lower government health spending on health and maternal health also is associated with higher maternal mortality. ${ }^{8}$

Level I delay have been seen by many researchers in India even in Tertiary care institutions. ${ }^{7,9,10}$ The ANC visits lack in the quality, many being given only the supplementation by the front-line workers but missing the chance to pass important information on danger signals of complications and when to seek care. Also, no professional visits mean the opportunity to screen for preexisting health ailments and obstetric complications such as mal-presentation is lost. Time is lost also due to the understanding about pregnancy and childbirth related phenomenon as a natural one and hence the symptoms are not promptly addressed and sought care of. ${ }^{11}$ In a study in Kerala, poverty, fear of health system and gender norms played an important role in the first delay. Many a time, patients are weary of going to the higher and bigger health care facilities due to the size of the facility which gets overwhelming to the patient, as well as the health care providers in the nearby facilities are known to the patients hence they lose precious time in reaching the health care facility (UP). ${ }^{12}$

Although not much found in isolation, level 2 delay was found in about $16 \%$ of the cases with other delays or in isolation. Many studies in India have found higher level II delay ranging from Geographic distribution of health facilities, cost of transport, unavailability of transport. ${ }^{12-15}$ 
Khandale et al found that the delay was majorly in first level, $86 \%$ in a tertiary care hospital in an urban area of Maharashtra state, although in the current study the first level delay is $27 \% .^{10}$ This difference may be a result of better health care facilities in the urban area, whereas the availability of better facilities in terms of obstetric ICU, blood facilities and the availability of trained personnel in the rural area may be the cause for higher level III delay found in current study.

A study at the secondary level health facilities, acting as first referral unit in North India has revealed that $56 \%$ of the women were referred due to non-availability of neonatal ICU, and $44 \%$ of the women were referred as the emergency $\mathrm{C}$ section facilities were unavailable, including that of the trained personnel. ${ }^{16}$ This results in losing precious time and thus worsening the complication.

Thus, the cases that reach the tertiary care hospitals are delayed and more complicated. A Meta-analysis on third delay in developing countries reveals how the level 3 delay, getting appropriate care has been a major preventable cause for maternal deaths. ${ }^{17}$ WHO 2005 report says that $50-70 \%$ can be prevented only with getting access to appropriate and good quality care. ${ }^{18}$ The most commonly seen barriers in the meta-analysis, as also seen in this study, skilled health professionals (86\%), availability of drugs/ other components $(65 \%)$, staff shortages (60\%) and low staff motivation (44\%). ${ }^{17,18}$

A plethora of programs have been working to decrease the maternal mortality and improve maternal heath indicators under National Health Mission; Janani Suraksha Yojana (Demand promotion Scheme) since 2005, Janani Shishu Suraksha Karyakram since 2013, Pradhan Mantri Suraksha Matritva Abhiyan, Iron and Folic Acid supplementation for prevention of anaemia, supplementation of calcium, deworming, Maternal Death and maternal near miss Review, Comprehensive Abortion care services, dissemination of newer guidelines, management of DM, hypothyroidism during pregnancy, syphilis screening, prevention of STI and RTI including HIV, community distribution of misoprostol for prevention of $\mathrm{PPH}$, newer guidelines and manuals for training of health personnel, capacity building of MBBS doctors in Anaethesia, EmOC, SBA training, focus on high priority districts with increased funding, relaxed norms and technical assistance through partners, performance based incentives for human resource, engagement of ASHAs, web-enabled mother and child tracking scheme, mother and child protection card, supervision and monitoring, involvement of ICDS for improving nutrition of adolescent girls, pregnant and lactating mothers, Pradhan Mantri Matru Vandana Yojana for conditional cash transfers. ${ }^{4}$ Even though India has made a great leap in Institutional deliveries through various schemes, the institutions have not been readied and prepared for any and every sort of obstetric cases, which is a case of policy gap. ${ }^{19}$

\section{CONCLUSION}

The study concludes that three delay model for emergency obstetric care in this tertiary care setting highlights the urgent need to focus on the availability of better health infrastructure including dedicated intensive care facilities for complicated labour, better quality manpower for better management of complicated cases. Also, wastage of time in referring from one facility to another demands better triage and co-ordination and transport facilities to reduce the time in bringing the women in distress to the desired point of care. Highly effective emergency obstetric care is the key to reducing maternal mortality and the associated severe morbidity and policy accountability in tandem with the implementation of various programs can make it so.

\section{Funding: No funding sources}

Conflict of interest: None declared

Ethical approval: The study was approved by the Institutional Ethics Committee

\section{REFERENCES}

1. Maine D. Safe motherhood programs: Options and Issues. New York: Centre for population and Family Health, Columbia University, 1991.

2. Trends in maternal mortality: 1990 to 2015: estimates by WHO, UNICEF, UNFPA, world bank group and the united nations population division. Available

at http://www.who.int/reproductivehealth/publications/ monitoring/maternal-mortality-2015/en/.

3. Special bulletin on maternal mortality in India 201416. Sample Registration System. Registrar General of India. 2018.

4. Millennium development goals. India country report 2015. Available at http://mospi. nic.in/sites/default/files/publication_reports/mdg_2ju ly15_1.pdf.

5. Thaddeus S., Maine D. Too far to walk: Maternal mortality in context. Soc Sci Med. 1994;38(8):1091110.

6. WHO 2018. Maternal mortality. Available at http://www.who.int/news-room/fact-sheets/ detail/maternal-mortality.

7. Murthy BK, Murthy MB, PM, P. Maternal mortality in a tertiary care hospital: A 10-year review. Int $\mathbf{J}$ Preventive Med. 2013;4(1):105-9.

8. Maruthappu M, Ng KY, Williams C, Atun R, Agrawal P, Zeltner T. The association between government healthcare spending and maternal mortality in the European Union, 1981-2010: a retrospective study. BJOG: Int J Obstet Gynaecol. 2015;122(9):1216-24.

9. Paul B, Mohapatra B, Kar K. Maternal deaths in a tertiary health care centre of Odisha: An in-depth study supplemented by verbal autopsy. Indian J Comm Med. 2011;36:213-16. 
10. Khandale, S.N., Kedar K. Analysis of maternal mortality: a retrospective study at tertiary care centre. Int J Reprod Contracept Obstet Gynecol. 2017;6(4):1610-3.

11. Mahapatro M. Equity in utilization of health care services: perspective of pregnant women in southern Odisha, India. Indian J Med Res. 2015;142(2):183.

12. Bhattacharyya S, Issac A, Rajbangshi P, Srivastava A, Avan BI. "Neither we are satisfied nor they"-users and provider's perspective: a qualitative study of maternity care in secondary level public health facilities, Uttar Pradesh, India. BMC Health Services Res. 2015;15(1):421.

13. Jithesh V, Ravindran TS. Social and health system factors contributing to maternal deaths in a less developed district of Kerala, India. J Reprod Health Med. 2016;2(1):26-32.

14. Sri BS, Khanna R. An investigation of maternal deaths following public protests in a tribal district of Madhya Pradesh, central India. Reprod Health Matters. 2012;20(39):11-20.

15. Subha BS, Khanna R. Dead women talking: a civil society report on maternal deaths in India. Common health and Jan Swasthya Abhiyan. 2014. Available at http://www.
commonhealth.in/DeadWomenTalkingfullreportfinal .pdf.

16. Kant S, Kaur R, Malhotra S, Haldar P, Goel AD. Audit of emergency obstetric referrals from a secondary level hospital in Haryana, North India. J Fam Med Primary Care. 2018;7(1):137-41.

17. Knight HE, Self A, Kennedy SH. Why are women dying when they reach hospital on time? a systematic review of the 'third delay'. PLoS ONE 2013;8(5):e63 846.

18. WHO (2005) The world health report 2005 - make every mother and child count, World Health Organization, Geneva.

19. Hamal M, Dieleman M, De Brouwere V, de Cock Buning T. How do accountability problems lead to maternal health inequities? A review of qualitative literature from Indian public sector. Public Health Rev. 2018;39(1):9.

Cite this article as: Ghumare JP, Padvi NV. Assessment of maternal deaths using three delay model at a tertiary care centre in rural Maharashtra, India: retrospective six years study. Int J Reprod Contracept Obstet Gynecol 2018;7:3043-7. 